\title{
Fluted films
}

N. B. Speirs, ${ }^{1}$ M. M. Mansoor, ${ }^{1}$ J. Belden, ${ }^{2}$ R. C. Hurd, ${ }^{1}$ Z. Pan, ${ }^{1}$ and T. T. Truscott ${ }^{1, *}$

${ }^{1}$ Department of Mechanical and Aerospace Engineering, Utah State University, Logan, Utah 84322, USA

${ }^{2}$ Naval Undersea Warfare Center, Newport, Rhode Island 02841, USA

Q (Received 31 January 2018; published 17 October 2018)

This paper is associated with a poster winner of a 2017 APS/DFD Milton van Dyke Award for work presented at the DFD Gallery of Fluid Motion. The original poster is available from the Gallery of Fluid Motion, https://doi.org/10.1103/APS.DFD.2017.GFM.P0030

DOI: 10.1103/PhysRevFluids.3.100504

A mass of water suddenly released from a vertical tube can take on the shape of a fluted champagne glass as it falls downward, as seen in Fig. 1. The acceleration of the fluid is opposed by shear

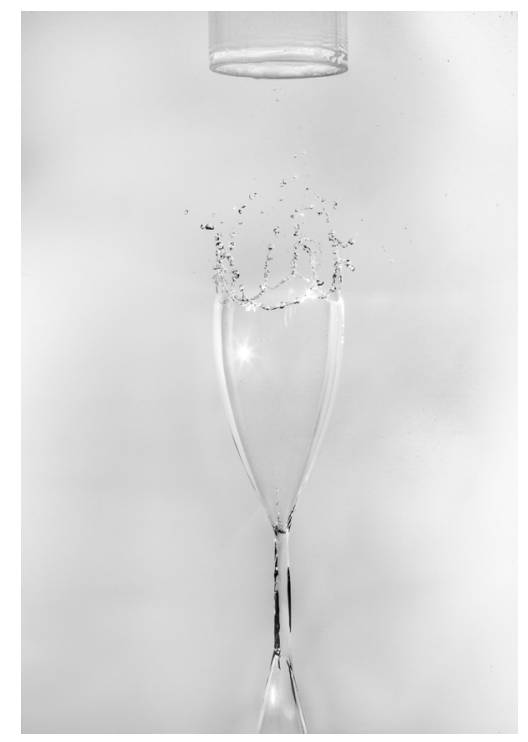

FIG. 1. A high-resolution photograph reveals a thin film of water trailing behind a large mass of water released from a downward-facing tube. The main water mass is below the frame. The film has detached from the tube and collapsed inward (bottom quarter of image). The structure is reminiscent of a champagne flute, with the water column forming the stem and the retracting film forming the bowl. The rim is decorated with satellite droplets from the retreating film border.

\footnotetext{
*taddtruscott@gmail.com
}

Published by the American Physical Society under the terms of the Creative Commons Attribution 4.0 International license. Further distribution of this work must maintain attribution to the author(s) and the published article's title, journal citation, and DOI. 

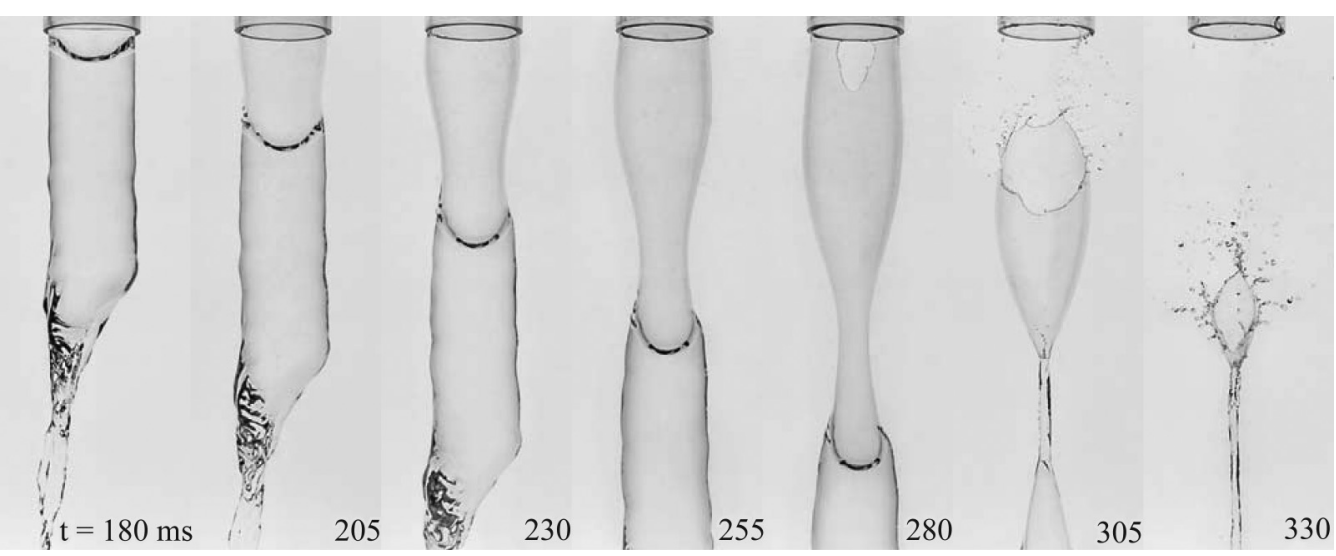

FIG. 2. A mass of water suddenly released from a polycarbonate tube with a 50-mm diameter results in the formation of an upside-down water bell. The bulk of the water mass begins to exit the tube after release at $t=0$ ms. The trailing free surface exhibits a concave shape shortly after the bulk of the water mass has exited the tube $(180 \mathrm{~ms})$. As the mass continues to fall, a thin tubular film connects the water mass to the tube exit (205-255 ms). The thin film contracts radially inward (230-280 ms), collapsing on itself, forming a liquid column ( $\approx 305 \mathrm{~ms})$. At approximately $280 \mathrm{~ms}$, the film ruptures at the edge of the tube, leading to full detachment of the film from the tube near $305 \mathrm{~ms}$.

stresses near the wall (no-slip), resulting in a flow moving faster along the center and slower near the wall. As a result, a thin tubular film connects the falling water mass to the tube exit from above (Fig. 2, $t=180-255 \mathrm{~ms}$ ). The film lengthens and thins as the water mass descends away from the tube exit. Surface tension and a pressure differential from internal airflow cause the tubular film to collapse radially inward, similar to a collapsing splash crown seen in a water entry event [1]. The collapse zips the film into a narrow water column downstream as seen in Fig. 2 at $t=305$ and $330 \mathrm{~ms}$.

Just prior to the formation of the narrow water column, the top of the tubular bubble thins enough to rupture and detach from the tube at $t=280 \mathrm{~ms}$. The film completely detaches by $t=305 \mathrm{~ms}$ and an upside down "water bell" [2,3] forms, a structure reminiscent of a champagne flute. After detachment, the champagne-flute shape does not preserve its shape during free fall. Rather, the film continues to collapse and drain into the water column as indicated by the lengthening of the column, retraction of the film bowl, and the fixed height of the top of the column with respect to the tube.

A photograph of a repeated event is shown in Fig. 1, just at the moment when the champagne-flute shape appears. The accumulation of water at the retreating film border decorates the rim of the glass with satellite droplets, resembling a champagne splash from a joyful clink.

We acknowledge funding from the Office of Naval Research, Naval Research Enterprise Internship Program (NREIP) and the Navy Undersea Research Program (NURP Grant No. N0001414WX00811).

[1] J. O. Marston, T. T. Truscott, N. B. Speirs, M. M. Mansoor, and S. T. Thoroddsen, Crown sealing and buckling instability during water entry of spheres, J. Fluid Mech. 794, 506 (2016).

[2] F. L. Hopwood, Water bells, Proc. Phys. Soc., Sect. B 65, 2 (1952).

[3] G. N. Lance and R. L. Perry, Water bells, Proc. Phys. Soc., Sect. B 66, 1067 (1953). 